\title{
Effect of Partially Premixed Fuel on Performance and Emission Characteristics of Compression Ignition (CI) Engine
}

\author{
B.Yogaprakash, R.Vijayakumar, S. Gowthaman, S.Bagavathi,
}

\begin{abstract}
In this world, the population is increased and the number of vehicles increased. Not only population the pollution is increased lot by vehicles in the world harmful pollutant is realized from the vehicles like $\mathrm{CO}, \mathrm{HC}, \mathrm{NOx}$ and smoke particulates. It is inevitable to find some new technology, which increases the better performance and emission characteristics. Partially premixed compression ignition (PCCI) is the best technology for the reducing of harmful pollution in the vehicle, which uses the diesel as fuel it, gives the advantages of both $C I$ and SI engine. This paper investigates the performance and emission characteristics of partially premixed diesel engine. Diesel engine has two injectors of port fuel injector (PFI) and direct injector $(D I)$ to inject the fuel in different timing and electrical control unit (ECU) passes the power to PFI; it can control the injection timing and increases the fuel content from the fuel pump. The main aim in this paper is studied is effect of partially premixed ratio, performance of engine and emission characteristics of diesel engine.
\end{abstract}

Keywords - Premixed ratio, injection timing, engine performance, PPCI engine, emission characteristics.

\section{INTRODUCTION}

$\mathrm{T}$ he day-by-day facing challenge of increasing pollution in the vehicles is very harmful to the people in the world. It is inevitable to find the some new technology for better performance and emission characteristics of the PPCI engine. Both SI and CI engine is advanced for PPCI engine to reduce the harmful emission like $\mathrm{NOx}, \mathrm{HC}, \mathrm{CO}$ and smoke particulates. The diesel is use as a fuel to inject the fuel from PFI and DI with different varies of timing. PFI is connected with ECU and fuel pump when the proximity sensor is sending a information after the two rotation of the crankshaft then the ECU pass power supply to the pump and PFI to inject the fuel in the intake valve. The fuel of PFI injects the fuel of $(10 \%, 20 \%, 30 \%, 40 \%$, and $50 \%)$ for the

Revised Manuscript Received on December 05, 2019.

* Correspondence Author

B. Yogaprakash, , UG Student, Department of Automobile Engineering Kalasalingam Academic of Research and Education, Krishnankoil, Srivilliputtur, Tamilnadu, India-626126,

R. Vijay Kumar, UG Student, Department of Automobile Engineering Kalasalingam Academic of Research and Education, Krishnankoil, Srivilliputtur, Tamilnadu, India-626126,

S. Gowthaman, Associate professor, Department of Automobile Engineering Kalasalingam Academic of Research and Education, Krishnankoil, Srivilliputtur, Tamilnadu, India-626126, Email: gowthammech@hotmail.com

Bagavathi, UG Student, Department of Automobile Engineering Kalasalingam Academic of Research and Education, Krishnankoil, Srivilliputtur, Tamilnadu, India-626126, partially premixed ratio in combustion chamber. The DI injects the fuel $(90 \%, 80 \%, 70 \%, 60 \%$ and $50 \%)$ after the compression stroke. Then the piston moves to TDC in the power stroke and the air and fuel mixture is compressed then the temperature increases in the combustion chamber and the $\mathrm{A} / \mathrm{F}$ mixture burns and the piston moves to TDC in the exhaust stroke and the unburned gasses moves out through the exhaust valve. The exhaust gas is passes to inter-link valve of exhaust to intake valve to passes the hot air into the intake with controlling the hot air with pressure control valve. The again the process repeats and applying of different types of loads $(1.1 \mathrm{KW}, 2.2 \mathrm{KW}, 3.3 \mathrm{KW}, 4.4 \mathrm{KW}$ and $5.2 \mathrm{KW}$ ) in the each fuel percentage. By compared with HCCI engine the PPCI engine is better for fuel consumption. And the PPCI engine as no charge ignition in the engine it as the combustion process and ignite the $\mathrm{A} / \mathrm{F}$ mixture and burns it. The HCCI engine has the charge combustion to ignite the fuel in combustion process and the unburned gasses percentage is more than the PPCI engine. The partially premixed ration is different in varies stages of load and the emissions reduces in $\mathrm{NOx}, \mathrm{HC}, \mathrm{CO}$, and smoke density. Brake thermal efficiency is increases the pressure by the fuel mode in the PPCI engine.

\section{EXPERIMENTAL SETUP ANDPROCEDURE}

The research engine is used with single cylinder of 4-stroke engine with some modification of the kirloskar engine and stetted up with some external equipment like PFI and DI injector, electrical control unit (ECU) is connected with the PFI and fuel pump. The PFI is placed in the intake valve and the DI injector is placed in top of the cylinder head. The proximity sensor is connected with ECU near the crankshaft. When the crankshaft rotates twice then the information passes to the ECU and the power supplies to the PFI and the fuel injects in the suction stroke. The outside fresh air is enters through the intake and the air and fuel is mixed partially in the combustion chamber after that the compression process starts at the end of the compression process the DI injects the fuel directly on the piston head and the $\mathrm{A} / \mathrm{F}$ mixture compressed then the temperature increases in the combustion process and the $\mathrm{A} / \mathrm{F}$ mixture burns and send out through the outlet valve in the exhaust stroke. 


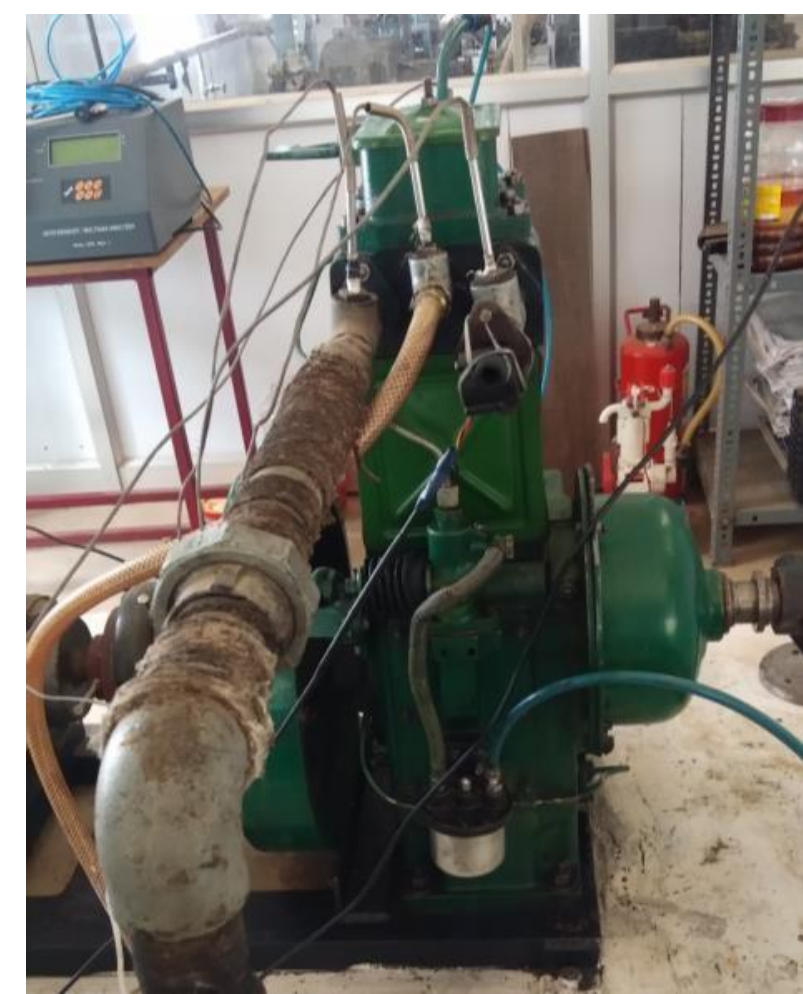

Figure.1 Experimental Setup

\begin{tabular}{|l|l|}
\hline Engine & Kirloskar Engine \\
\hline Type & $\begin{array}{l}\text { Single Cylinder, } \\
4 \text { stroke Diesel Engine }\end{array}$ \\
\hline Bore X Stroke & $87.5 \mathrm{~mm} \mathrm{X} \mathrm{110} \mathrm{mm}$ \\
\hline Compression Ratio & $17.5: 1$ \\
\hline Fuel & Diesel \\
\hline Rated Brake Power & $5.2 \mathrm{kw}$ \\
\hline Speed & $1500 \mathrm{rpm}$ \\
\hline Ignition system & Compression Ignition \\
\hline Ignition Timing & $23^{\mathrm{O}} \mathrm{bTDC}$ \\
\hline Injection Pressure & $220 \mathrm{kgf} / \mathrm{cm}^{2}$ \\
\hline Loading Device & $\begin{array}{l}\text { Eddy } \\
\text { Dynamometer }\end{array}$ \\
\hline Orifice Diameter & $0.02 \mathrm{M}$ \\
\hline $\begin{array}{l}\text { Dynamometer Arm } \\
\text { Length }\end{array}$ & $0.195 \mathrm{M}$ \\
\hline
\end{tabular}

In the PPCI engine, the PFI timing is varied in different $(10 \%, 20 \%, 30 \%, 40 \%$ and $50 \%)$ by the change the time in the ECU the fuel percentage is increased and the time is set in microseconds in the ECU. The DI $(90 \%, 80 \%, 70 \%, 60 \%$ and $50 \%$ ) will inject the remaining fuel at the end of the compression stroke. The inlet valve is connected with the outlet valve to pass the hot air to the inlet valve with the pressure control valve.

\section{Performance Characteristics}

Specific fuel consumption is a very much important parameter to be observed the engine performance. The fuel consumption and calorific value of fuel have shown in the in above figure. The varies of fuel consumption is with respected to premixed ratio. The fuel consumption is reduced with increasing of load. The diesel operation in fuel consumption is $(0.6,0.64,0.66,0.68$ and $0.70 \mathrm{MJ} / \mathrm{KW})$ at $(1.1,2.2,3.3,4.4$ and $5.2 \mathrm{KW})$ load. Increases the premixed ratio value of fuel consumption is almost equal to the higher load and lower load consume more energy.

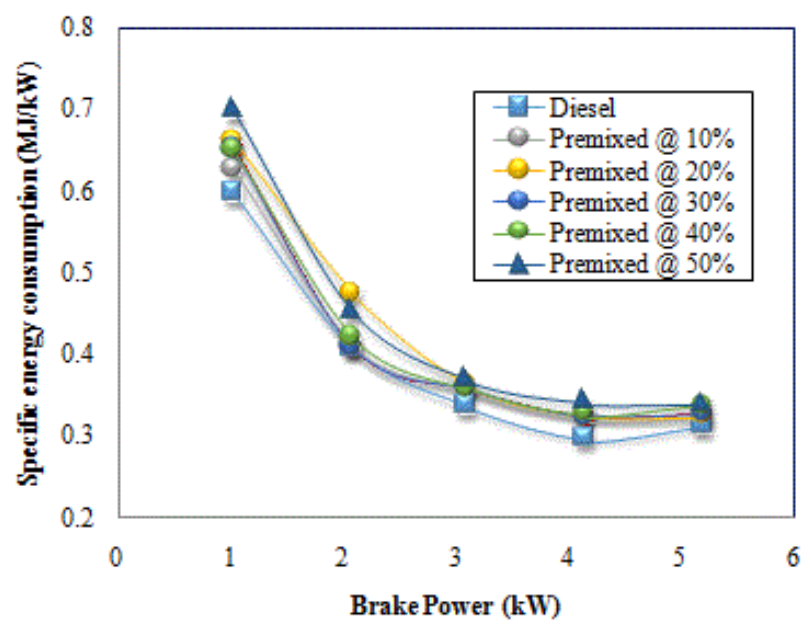

Figure: 1. Specific energy Consumption

The variation of brake thermal efficiency with premixed ratio on various applied load is shown in above figure. The brake thermal efficiency is increased in the diesel fuel mode. Brake thermal efficiency increases from lower load to higher load and indicates the capacity of combustion system and coverts the fuel energy to mechanical energy. In full load brake thermal efficiency, the combustion efficiency is maximum. In full load brake thermal efficiency is 27.13 .

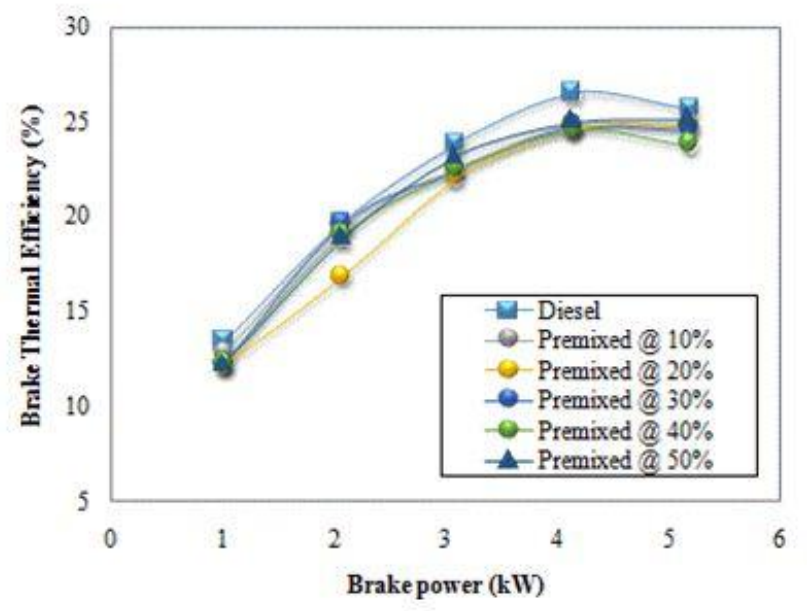

Fig. 3 Brake thermal efficiency

\section{EMISSION CHARACTERISTICS}

The smoke density is varied from the premixed ratio. Smoke density is decreased and premixed ratio increased. The mixture is more in homogeneous and combustion is efficient at $1.1,2.2$ and $3.3 \mathrm{KW}$ load decreases the smoke density. 


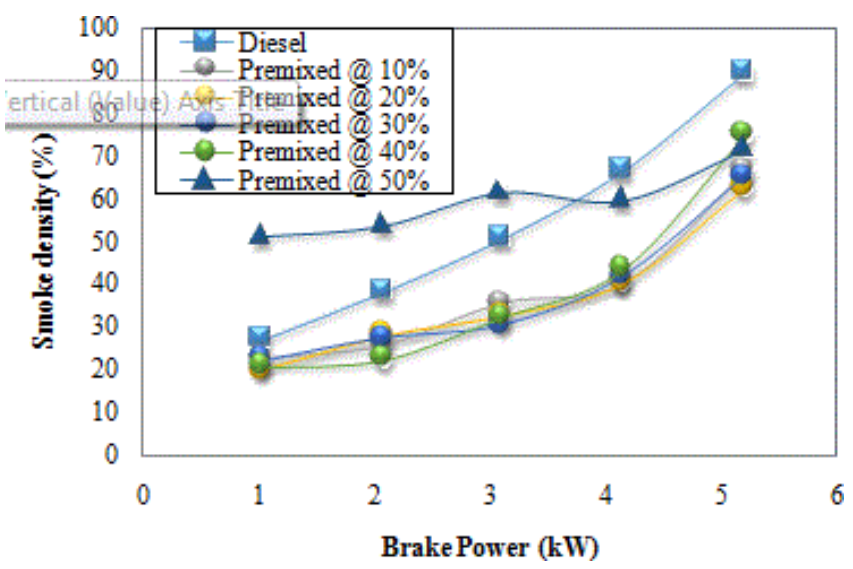

Figure.4 Smoke densities

The increase of inlet temperature is increases the emission of NOx. NOx is varied from the premixed ratio. At full load, the NOx is reduced and the diesel is reduced. At higher premixed ratio, the NOx is reduced to $40 \%$.

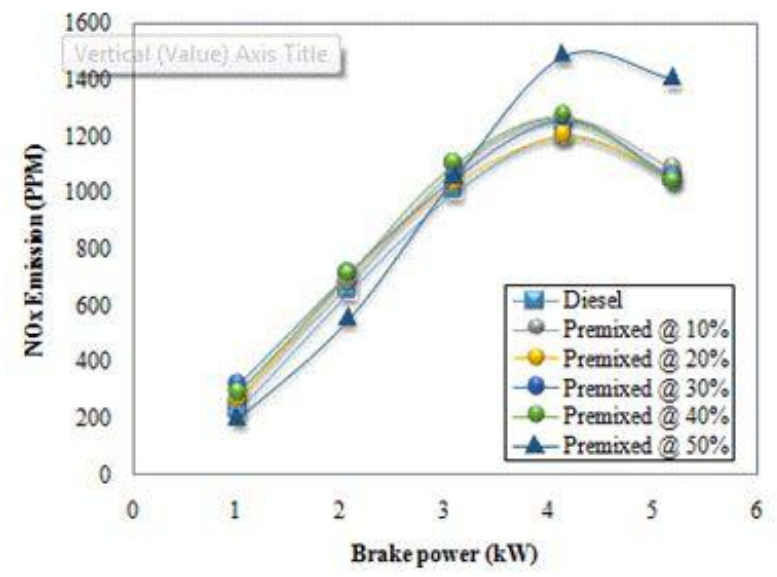

Figure.5 Nitrous oxide

The higher carbon monoxide in exhaust gas is inefficient combustion. In premixed ratio, the $\mathrm{CO}$ emission is incomplete. Nearly at $40 \%$ of $\mathrm{CO}$ emission is reduced. At full load the $\mathrm{CO}$ emission is incomplete and the starting load the emission is normal. At the middle stage the emission reduced to $40 \%$ in load $3.2 \mathrm{KW}$ and $4.3 \mathrm{KW}$.

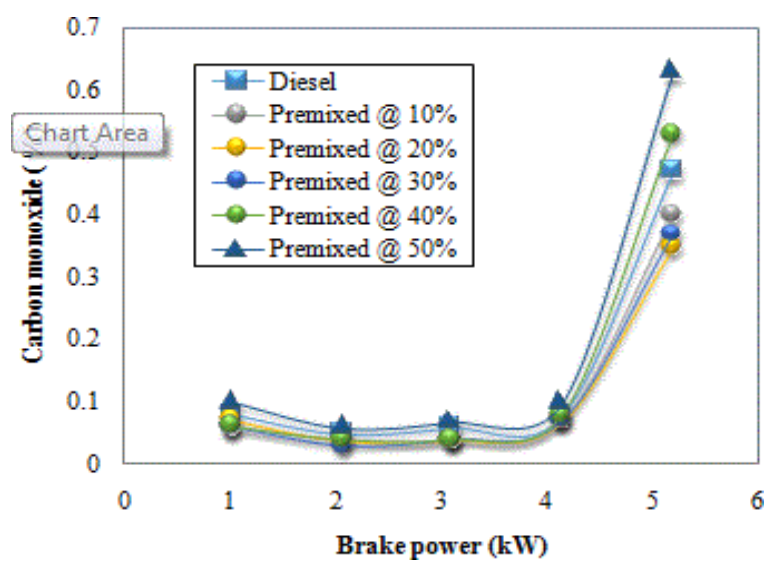

Figure.6 Carbon monoxide

The result of the $\mathrm{HC}$ emission is incomplete combustion in the diesel fuel. At the $40 \%$ of the premixed ratio and load
$3.2 \mathrm{KW}$, the $\mathrm{HC}$ emission is reduced. In the full load the emission is increasedwith, approximate to the diesel fuel.

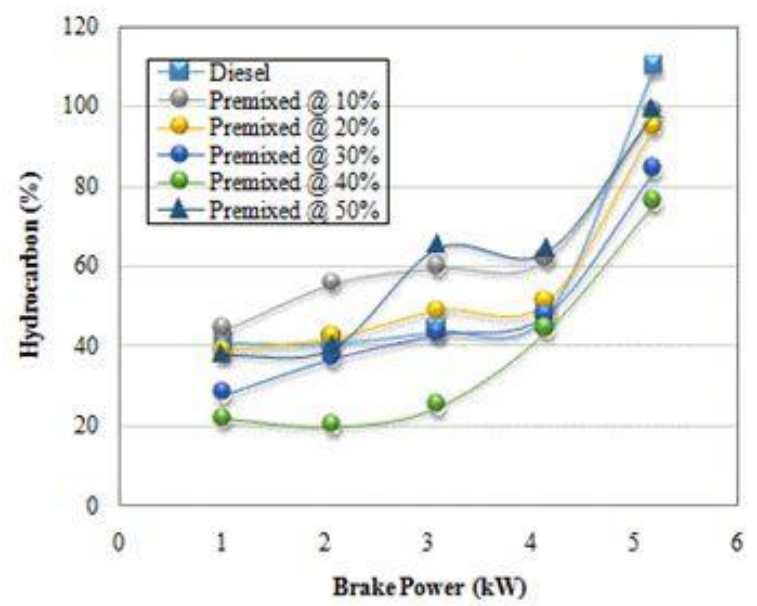

Figure.6 Hydrocarbon

\section{CONCLUSION}

Performance and emission characteristic of the 4stroke kirloskar diesel engine is modified with some change for reducing of emissions percentage. Different loads are applied in the different premixed ratio separately.

- At full load operation, the emission of NOx, CO, HC and smoke density not reduced and combustion is uncontrolled when the premixed ratio is increased.

- In the $3.2 \mathrm{KW}$ and $4.2 \mathrm{KW}$ load, the $40 \%$ of the premixed ratio the emission of $\mathrm{NOx}, \mathrm{HC}$ and $\mathrm{CO}$ is reduced. The smoke density is high in the particular load.

- $\quad$ At the $2.2 \mathrm{KW}$ load, the $\mathrm{HC}, \mathrm{CO}$ and smoke density is low and the NOx emission is increased. In the brake, thermal efficiency at $2.2 \mathrm{KW}$ load the efficiency is higher and the fuel consumption is low in this load. This show some negative performance and emission characteristics.

- In the $1.1 \mathrm{KW}$ load the performance and emission characteristics shows the normal result, where same as to the specific fuel consumption and the brake thermal efficiency.

\section{REFERENCES}

1. J.W. Chung, J.H. Kang, N.H. Kim, W. Kang and B.S. Kim, "Effects of the Fuel Injection Ratio on the Emission and Combustion Performances of the Partially Premixed Charge Compression Ignition Combustion Engine Applied with the Split Injection Method," International Journal of Automotive Technology, IX, (1), pp: 1-8, 2008.

2. M. Lewander, B. Johansson, T.N. Keeler, S. Tullis and N.M. Pär Bergstrand, 'Evaluation of the Operating Range of Partially Premixed Combustion in a Multi Cylinder Heavy Duty Engine with Extensive EGR,” SAE paper No. 2009-01-1127, 2009.

3. Pawan Kumar Tiwari. Experimental Investigation of Ethanol fuelled Partially premixed compression ignition (PPCI) Diesel engine.IJMER ISSN (Print) : 2321-5747, Volume-4, 
4. Kokjohn, S. and Reitz, R. (2010). Characterization of dualfuel PCCI combustion in a light-duty engine. Int. Multidimensional Engine Modeling User's Group Meeting.

5. S. Lee and R.D. Reitz, "Spray Targeting to Minimize Soot and CO Formation in Premixed Charge Compression Ignition (PCCI) Combustion with a HSDI Diesel Engine," SAE Technical Paper Series, 2006-01-0918, 2006.

6. T. Li, M. Suzuki and H. Ogawa, "Characteristics of Smokeless Low Temperature Diesel Combustion in Various Fuel-Air Mixing and Expansion of Operating Load Range," SAE Paper 2009-01-1449, 2009.

7. W. De Ojeda, P. Zoldak, R. Espinosa and R. Kumar, "Development of a Fuel Injection Strategy for Diesel LTC," SAE Paper No. 2008- 01-0057, 2008.

8. Sjöberg, M. and Dec, J., "Smoothing HCCI Heat-Release Rates Using Partial Fuel Stratification with Two-Stage Ignition Fuels," SAE Technical Paper 2006-01-0629, 2006, doi: 10.4271/2006-01-0629.

9. Leermakers, C., Luijten, C., Somers, L., Kalghatgi, G. et al., "Experimental Study of Fuel Composition Impact on PCCI Combustion in a Heavy-Duty Diesel Engine," SAE Technical Paper 2011-01-1351, 2011, doi:10.4271/201101-1351.

10. Kokjohn, S., Hanson, R., Splitter, D., and Reitz, R., "Experiments and Modeling of Dual-Fuel HCCI and PCCI Combustion Using InCylinder Fuel Blending," SAE Int. J. Engines 2(2):24-39, 2010, doi: 10.4271/2009-01-2647.

\section{AUTHORS PROFILE}

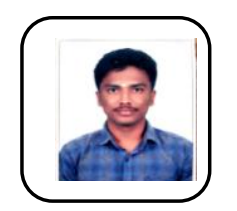

B. Yogaprakash, (B.E.,), UG student

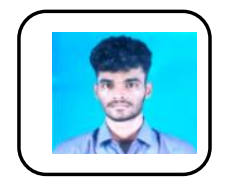

R. Vijaykumar, (B.E.,) UG student

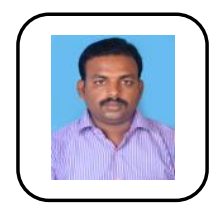

Dr. S Gowthaman, Ph.D., (IC engines), Published 11 papers in international publications, and membership in ISTE,. 